\title{
Construction and Evaluation of a Novel Internal Positive Control (IPC) for Detection of Coxiella burnetii by PCR
}

\author{
Keivan Majidzadeh ${ }^{1,2}$; Amirhossein Mohseni ${ }^{1}$; Mohammad Soleimani ${ }^{1, *}$ \\ ${ }^{1}$ Tasnim Biotechnology of Research Center (TBRC), Faculty of Medicine, AJA University of Medical Sciences, Tehran, IR Iran \\ ${ }^{2}$ Cancer Genetics Research Group, Breast Cancer Research Center (BCRC), ACECR, Tehran, IR Iran \\ ${ }^{*}$ Corresponding author: Mohammad Soleimani, Tasnim Biotechnology Research Center (TBRC), AJA University of Medical Sciences, Etemadzadeh Ave, West Fatemi, Tehran, IR Iran. \\ Tel: +98-2188337928, Fax: +98-2188337928, E-mail: soleimanidor@yahoo.com
}

Received: November 4, 2012; Revised: February 19, 2013; Accepted: April 23, 2013

\begin{abstract}
Background: Due to the limitations of the classical methods to detect Coxiella burnetii, direct diagnosis of the pathogen using PCR techniques is still the preferable approach. However, false negative results owing to the presence of PCR inhibitors are troublesome.

Objectives: In order to identify the inhibitors during PCR assay, an internal positive control (IPC) was designed based on 16SrRNA gene of C. burnetii.

Materials and Methods: In the current study, the initial and ending parts of the target gene in an external positive control plasmid (pTZ57R/T-16S) amplified using internal primers which had a BglII restriction site on the $5^{`}$ ends. Both PCR products (fragments 1 and 2) were cloned into pTZ57R/T vector. Following BglII enzyme digestion, the two obtained linear plasmids were ligated. The ligation product was transformed into Escherichia coli Top10 F'. Screening of the desired recombinant clone was carried out using colony PCR.

Results: The size of the PCR product was equal to the sum of the first and second fragments. Sequencing confirmed the presence of the desire insert(IPC sequence) in recombinant plasmid. Consequently, the IPC fragment was longer than the target gene while both ends had similar attachments to the same primer pair.

Conclusions: The results showed that direct fusion of the recombinant plasmids containing the initial and ending parts of the target gene are simple and cost-effective techniques for increasing the length of the fragment and constructing IPC.

Keywords: Coxiella burnetii, Molecular Detection: Q Fever, Polymerase Chain Reaction
\end{abstract}

\section{Background}

Coxiella burnetii, an obligate intracellular bacterium, is the causative agent of Q-fever. This bacterium has been classified as a member of center for disease control (CDC) category $B$ biological agents due to its high transmission potential. Since the bacterium is an intracellular obligatory parasite, its culturing needs a live host, which is very time-wasting, expensive and dangerous and just laboratories with level 3 of biological safety and expert staff are allowed to work on contaminated samples with this bacterium. Molecular techniques such as PCR are useful methods for rapid detection of the bacterium in biological samples $(1,2)$.

PCR-based technologies are rapid, sensitive, and specific for detection of infective agents that vastly developed diagnosis of a wide range of pathogens in clinical laboratories (3). However, high sensitivity of these approaches may lead to the increased number of false negative and false positive results (4). In addition to cross contamina- tion, false positive results may be due to contamination of samples with external positive controls (5-7), whilst false negative result is caused when PCR reaction fails to work properly as a result of expiration of reaction components, technique insufficiency (wreck of equipment and facilities) or the presence of nucleic acid amplification inhibitory substances.

Various PCR inhibitors such as EDTA, heparin, hemoglobin, ethanol and SDS may not remove during DNA extraction procedure and lead to reaction inhibition (814). Therefore, a strategy to provide the necessary information for accurate interpretation of PCR assay results is required. To monitor the false negative results of PCR, different standards have been developed (15). According to the guidelines of international standard organization (ISO), the presence of internal positive control (IPC) in the reaction is mandatory (16). Contrary to the external controls which are presented in a separate reaction tube, IPCs are a variety of control substances with a non-target DNA or a RNA sequence which are directly added to the

Implication for health policy/practice/research/medical education:

In order to identify the inhibitors in a PCR assay, an internal positive control (IPC) was design based on 16SrRNA gene of $C$. burnetii for PCR detection of $C$. burnetii.

Copyright @ 2014,Ahvaz Jundishapur University of Medical Sciences; Published by Kowsar Corp. This is an open-access article distributed under the terms of the Creative Commons Attribution License, which permits unrestricted use, distribution, and reproduction in any medium, provided the original work is properly cited. 
PCR reaction tubes $(16,17)$. Internal control could determine the failure of PCR caused by inhibitor effects. In addition, the presence of internal control could ensure the accuracy of the whole nucleic acid extraction procedure $(4,16,18,19)$. Nowadays, various strategies are used to make internal positive control for diagnostic PCR assays.

\section{Objectives}

In the present study, a unique internal positive control based on 16SrRNA of C. burnetii was constructed.

\section{Materials and Methods}

\subsection{Plasmid and Primer Design}

The pTZ57R/T-16S plasmid was used to create an IPC fragment for PCR detection of C. burnetii . In an earlier study by the authors, this plasmid had been generated by cloning of diagnostic PCR product of C. burnetii 16SrRNA (Accession number: D89799), sized 240 bp, into a pTZ57R/T plasmid and used as an external positive control ( 20 ). The 16SrRNA specific pair primers annealed to the oligonucleotides No.1-25 (forward primers; coc 1) and No. 216-240 (reverse primers; coc 4). Accordingly, an inner reverse primer ( $\operatorname{coc} 2$ ) was designed. Restriction site of BglII enzyme was added at 5 ' end of the primers. This primer annealed to the nucleotides No. 186-213 and amplified a $213 \mathrm{bp}$ fragment along with coc1 primer. Also, an inner forward primer $(\operatorname{coc} 3)$ was designed and restriction site for BglII enzyme also inserted into the 5 ' end of this primer. This primer annealed to nucleotides No. 71-97 and amplified a $170 \mathrm{bp}$ fragment along with coc 4 primer. Gene Runner (version 3.05; Hastings Software Inc., Hastings on Hudson, NY) was used for designing the primers (Table 1).

Table 1. The Sequences of the Primers Used in This Study

\begin{tabular}{|c|c|c|}
\hline Primer Name & Sequence $^{\mathrm{a}}$ & Annealing Site on Diagnostic 16S rRNA of $C$. burneti \\
\hline $\operatorname{coc} 1$ & $5^{`}$ ATATCCTTGGGCGTTGACGTTACCC $3^{-}$ & No.1-25 \\
\hline $\operatorname{coc} 2$ & 5`AATTCAGATCTCСTCTACСATACTCAAG $3^{-}$ & No. 186-213 \\
\hline $\operatorname{coc} 3$ & 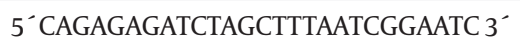 & No. 71-97 \\
\hline $\operatorname{coc} 4$ & $5^{\circ}$ ATCTACGCATTTCACCGCTACACCG $3^{-}$ & No. $216-240$ \\
\hline
\end{tabular}

$\mathrm{a}$ The Underlined Regions Show the BglII Restriction Sites

\subsection{PCR Reaction}

Two PCR reactions were set up using the designed primers. In the first reaction, primers $\operatorname{coc} 1$ and $\operatorname{coc} 2$ and in the second reaction, primers $\operatorname{coc} 3$ and $\operatorname{coc} 4$ were used. The PCR reactions were prepared according to the standard protocol in total volumes of $25 \mu \mathrm{L}$. In all reactions, pTZ57R/T-16S plasmid (50 ng) was used as DNA template. The reactions were run with annealing temperature at $52^{\circ} \mathrm{C}$.

\subsection{Cloning of the First and the Second Fragments}

PCR products related to primers Coc 1 and coc 2 (fragment one) and primers coc 3 and coc 4 (fragment two) purified using a commercial gel extraction kit (Bioneer, Korea). Ligation reaction of these fragments and pTZ57R/T vector was separately carried out by T4DNA ligase (Fermentas, Lithuania) for 3 hours at $22^{\circ} \mathrm{C}$. The ligation products were transformed into Escherichia coli TOP10F' and the cells were cultured onto LB agar medium containing IPTG (38.4 g/mL), X-gal (40 g/mL), ampicillin (100 g/mL) and tetracycline $(50 \mathrm{~g} / \mathrm{mL})$ and incubated overnight at $37^{\circ} \mathrm{C}$. The colonies receiving each of the two fragments were selected and confirmed. The plasmid of the confirmed recombinant colonies were separately extracted using AccuPrep plasmid mini extraction kit (Bioneer, Ko- rea). Finally, the confirmed plasmids named as pTV-frg 1 and pTV-frg 2 .

\subsection{Enzymatic Digestion}

Each of the plasmids pTV-frg 1 and pTV-frg 2 was separately digested and linearized using BglII (Fermentas, Lithuania). The digestion reaction was performed on 500 ng of each plasmid with 2 units of BglII in an appropriate buffer condition. Incubation was performed at $37^{\circ} \mathrm{C}$ for 16 hours. Finally the products were examined on $1 \%$ agarose gel.

\subsection{Fusion of Digested $p T V$-frg 1 and $p T V$-frg 2}

Since both pTV-frg 1 and pTV-frg 2 plasmids had been digested with the same enzyme, they had identical complementary sites. With regard to this competency, a ligation reaction was performed using T4DNA ligase (Fermentas, Lithuania) for 5 hours at $22^{\circ} \mathrm{C}$ between the two linearized plasmids. Finally, the products of the ligation reaction were transformed into the competent E.coli Top10F' cells. Transformed cells were selected as mentioned above. Screening of the desired recombinant colony (containing fused pTV-frg 1 and pTV-frg 2 or IPC plasmid) carried out by colony PCR using coc 1 and coc 4 primers. Cycle sequencing method using universal M13 primers per- 
formed for final confirmation of the fused recombinant construct. The sequencing results were checked by NEB cutter's online software V2.0 (http://tools.neb.com/NEBcutter2/) and BLAST (http://blast.ncbi.nlm.nih.gov/Blast.cgi). The confirmed recombinant plasmid containing the IPC sequence named pTZ57R/T-IPC.

\subsection{Determination of Optimum Concentration of the IPC}

To determine the optimum concentration of the IPC plasmid in PCR tubes of clinical specimens and its utility as an extraction control, the following experiment was conducted. A 10-fold serial dilutions ranging from $1 \mu \mathrm{g}$ to $1 \mathrm{pg} / \mu \mathrm{L}$ of $\mathrm{pTZ} 57 \mathrm{R} / \mathrm{T}$-IPC were prepared on non-infected blood samples. DNA isolation was carried out on all the IPC spiked samples by using a QIAamp® DNA Mini Kit (Qiagen Inc., Valencia, CA). The extracted DNA samples were subjected to a number of PCR reactions in the presence of $\operatorname{coc} 1$, $\operatorname{coc} 4$ primers and $1 \mathrm{ng}$ of pTZ57R/T-16S plasmid as the target DNA (this concentration was equal to the limit of detection of the method) (20). Consequently, the minimum concentration of the IPC, that did not affect the amplification of the target gene, presented as the op- timized concentration.

\section{Results}

\subsection{Preparation of Linear TV-frg1 and TV-frg2 Vectors}

The electrophoresis of PCR products using $\operatorname{coc} 1$ and coc 2 primers and coc 3 and coc 4 primers resulted in the expected products (213 bp and $170 \mathrm{bp}$, respectively) (data not shown). After cloning of both fragments and extraction of recombinant plasmids from white colonies, the presence of $213 \mathrm{bp}$ and $170 \mathrm{bp}$ fragments in TV-frg 1 and TV-frg 2 vectors, were confirmed using colony PCR. Enzymatic digestion on TV-frg 1 and TV-frg 2 vectors with BglII changed them into their linear forms. Observation of $3099 \mathrm{bp}$ and also 3056 bp bands on $1 \%$ gel agarose for TV-frg 1 and TV-frg 2 vectors respectively confirmed the accuracy of digestion (data not shown).

\subsection{Constructing IPC}

During the ligation process between linearized vectors pTV-frg 1 and pTV-frg 2, the creation of four arrangement states was possible (both ends of the linear vectors had BglII created overhangs) (Figure 1).

Figure 1. Schematic View of the Novel Strategy for IPC Construction Introduced in the Present Study

A
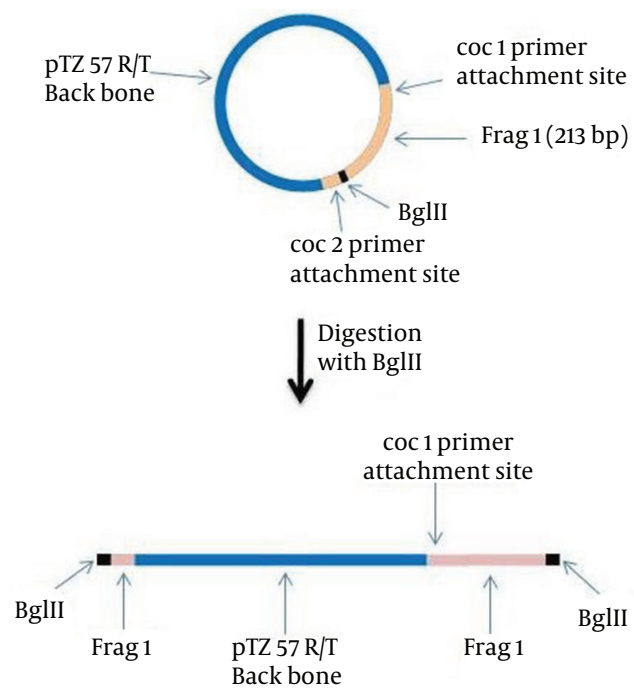

B

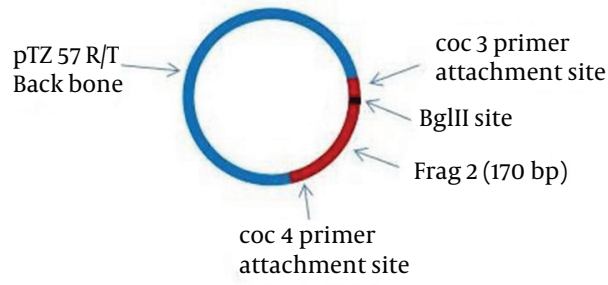

attachment site
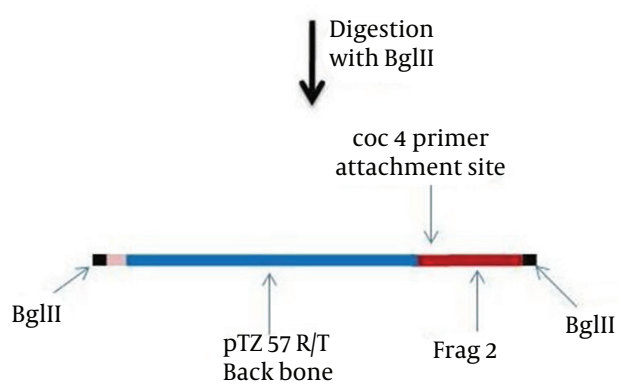

$\downarrow^{\text {Ligation }}$

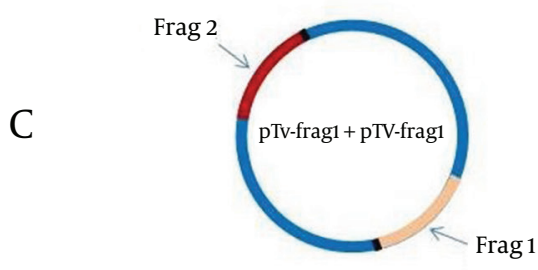

1

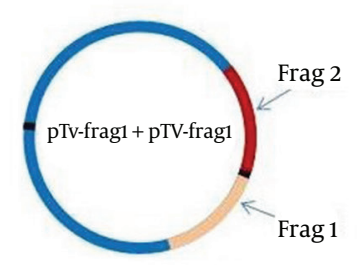

2

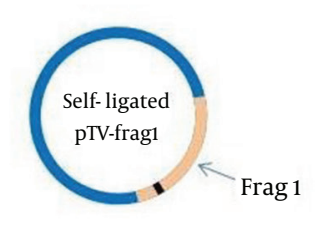

3

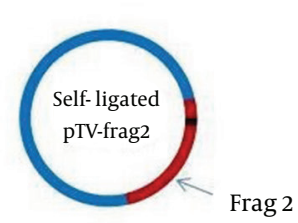

A:TA-cloning of frag $1(213 \mathrm{bp})$ and frag $2(170 \mathrm{bp})$ corresponding to the initial and ending parts of the diagnostic $16 \mathrm{SrRNA}$ gene of $C$. burnetii. B: BglII digestion of pTV-frag 1 and pTV-frag 2 and creating the linearized forms. C: Ligation and cloning of both linear plasmids. As seen in the figure, the constructed plasmid No. 2 containing the IPC segment. 
The colony receiving plasmid containing the complete sequence of IPC was identified by PCR using coc 1 and coc 4 primers. After IPC amplification, its PCR product showed a $367 \mathrm{bp}$ band (this product was equal to the sum of the first and second fragments sizes) (Figure 2).

Figure 2. The Results of PCR of Diagnostic 16SrRNA and the IPC Sequence Using $\operatorname{coc} 1$ and $\operatorname{coc} 4$ Primers

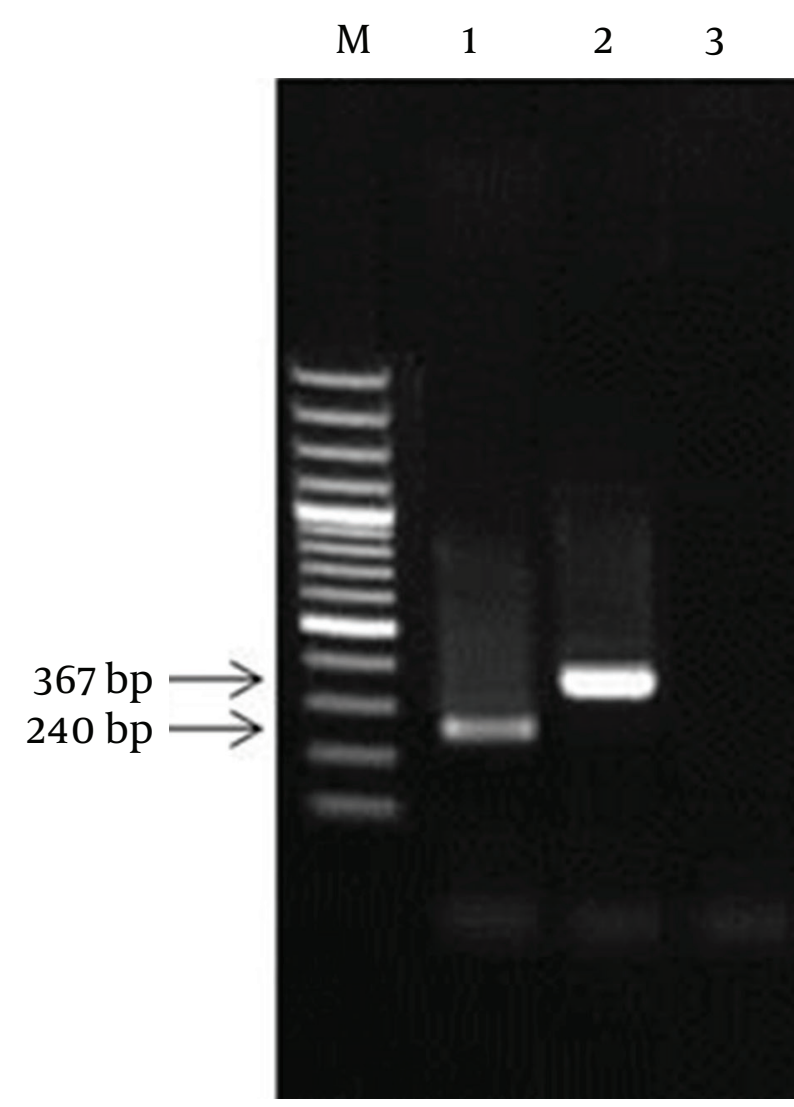

M: 100 bp DNA Marker; 1: PCR product of the diagnostic 16SrRNA; 2: PCR product of the IPC plasmid; 3: PCR negative control.

Consequently, the resulted fragment (IPC fragment) was longer than the target gene while both ends had similar sticky sites to the target gene. Following sequencing of internal positive control plasmid and preparation of its restriction map, BglII restriction site was found in nucleotides $203 \mathrm{bp}$ to $208 \mathrm{bp}$ of IPC sequence, as expected. Meanwhile, the comparison of restriction maps of IPC sequence and the PCR product of 16SrRNA diagnostic gene showed complete identity between the fragment one of IPC and the initial part of the diagnostic sequence, and between fragment two of IPC and the final part of diagnostic sequence.

\subsection{Optimized Concentration of the IPC}

The PCR tubes containing $1 \mu \mathrm{g}$ and $100 \mathrm{ng}$ of pTZ57R/TIPC, resulted in only amplification of IPC sequence (367 bp band). The PCR tubes containing $10 \mathrm{ng}$ and $1 \mathrm{ng}$ of
pTZ57R/T-IPC plasmid revealed amplification in both of the IPC and diagnostic 16srRNA gene (367 bp and $240 \mathrm{bp}$ ). In the tubes containing $100 \mathrm{pg}, 10 \mathrm{pg}$ and $1 \mathrm{pg}$ of pTZ57R/ T-IPC, only amplification of the diagnostic gene (240 bp) was observed (Figure 3). Finally, 1 ng of the IPC that showed a weak $367 \mathrm{bp}$ band in the presence of the lower limit of detection (1 ng) of 16SrRNA gene was determined as the optimized concentration to use in PCR reaction of clinical samples.

Figure 3. The Related Results to Optimization of the IPC Concentration

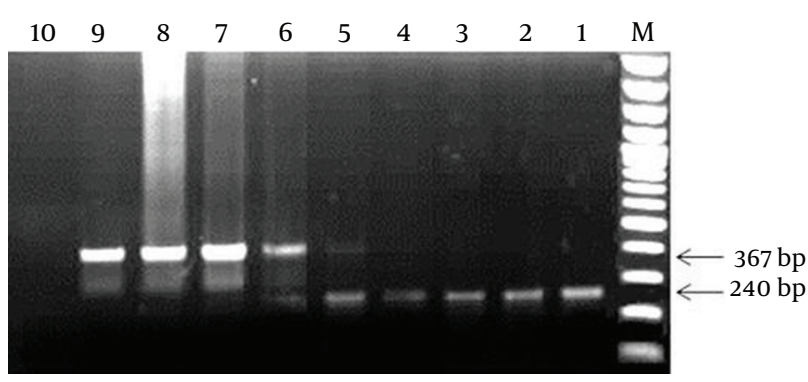

M:100 bp DNA Marker; 1: positive control for diagnostic 16SrRNA gene; 2-8: PCR products of the tubes containing $1 \mathrm{pg}$ to $1 \mu \mathrm{g}$ of pTZ57R/T-IPC plasmid in the presence of $1 \mathrm{ng}$ of pTZ57R/T-16S plasmid; 9: the IPC positive control; 10: Negative control. As seen in figure, the best concentration of IPC for use in the PCR reaction was $1 \mathrm{ng}$ concentration (well No. 5).

\section{Discussion}

In the present study, we developed a new competitive IPC. IPCs are classified as competitive and noncompetitive. Noncompetitive IPCs include a group of internal controls with primer annealing sites different from target gene. These controls usually belong to generic controls such as universal or housekeeping genes or are manually synthesized $(2,4,16)$. Murphy et al. developed a type of noncompetitive IPC; a microbiological internal positive control, for PCR based detection of Listeria monocytogenes and Salmonella enterica (4). Sohni and his colleagues, reported a microbiological noncompetitive IPC for detection of Bacillus anthrasis (21). Although these IPCs can take an important role in the accuracy of the results, they represent two limitations: 1) Live bacteria containing the IPCs should be apply in detection process. 2) Given the fact that two primer sets are used in a multiplex reaction, this could lead to interference of primers in the reaction and in some times could cause the formation of different primers dimers in the reaction and resulting in low sensitivity of the PCR reaction.

It is recommended to use competitive IPC instead of a noncompetitive IPC (16). Competitive IPCs have similar primer annealing sites for the target gene and are amplified by the same primer pairs and conditions along with the target gene $(16,17)$. In recent years, for making different competitive IPCs, several strategies have been used including altering size of target DNA by insertion, deletion, substitution or placing a new restriction site 
in the target DNA which is not present in the wild DNA type. Using the last strategy would add an extra step to the detection because following the PCR; the PCR product should be subjected to enzyme digestion. Occasionally, false negative results may occur due to fail of enzymatic digestions (22-28). Hodgson and his colleagues (2006) developed a competitive IPC for detection of HSV types 1 and HSV 2. They made a DNA fragment containing a primer annealing site for target gene with the heterologous region at the middle (derived from the pGEM plasmid) (22). One of the limitations for using the above strategies for producing IPC is that various steps and genetic engineering methods were applied, making the process difficult, complicated, time-consuming and costly whereas in the present study by a simple, easy and cost-effective strategy, an IPC fragment was developed. Since the constructed IPC was the competitive, the optimum concentration of IPC plasmid (pTZ57R/T-IPC) applicable in PCR reaction without any inhibitory effect on the amplification of the target gene was determined. The experiment showed that higher concentration of the IPC plasmid would prevent amplification of the target gene. In the current study, concerning the fact that IPC was longer than target gene in size, advantage in detection was seen because, in amplification competition between target gene and IPC, target gene is always successful.

The results of this study concluded that PCR amplification of overlapping initial and ending parts of a diagnostic gene, pasting the fragments and eventually cloning is a simple and cost-effective strategy to make longer target gene and a competitive IPC. This IPC could be routinely used for improved detection of target genes.

\section{Acknowledgements}

The authors would like to acknowledge and appreciate the faculty of medicine and AJA University of Medical Sciences for their support and contribution to this study.

\section{Authors' Contribution}

None declared.

\section{Financial Disclosure}

There is no financial interest.

\section{Funding/Support}

There is no funding/support.

\section{References}

1. Boulos A, Rolain JM, Maurin M, Raoult D. Measurement of the antibiotic susceptibility of Coxiella burnetii using real time PCR. Int J Antimicrob Agents. 2004;23(2):169-74.

2. Waag DM. Coxiella burnetii: host and bacterial responses to infection. Vaccine. 2007;25(42):7288-95.

3. Espy MJ, Uhl JR, Sloan LM, Buckwalter SP, Jones MF, Vetter EA, et al. Real-time PCR in clinical microbiology: applications for routine laboratory testing. Clin Microbiol Rev. 2006;19(1):165-256.
4. Murphy NM, McLauchlin J, Ohai C, Grant KA. Construction and evaluation of a microbiological positive process internal control for PCR-based examination of food samples for Listeria monocytogenes and Salmonella enterica. Int J Food Microbiol. 2007;120(12):110-9.

5. Cone RichardW, Hobson AnnC, Huang Meei-Liw, Fairfax MarilynnR. Polymerase chain reaction decontamination: the wipe test. The Lancet. 1990;336(8716):686-687.

6. Kwok S, Higuchi R. Avoiding false positives with PCR. Nature. 1989;339(6221):237-8.

7. Rys PN, Persing DH. Preventing false positives: quantitative evaluation of three protocols for inactivation of polymerase chain reaction amplification products. J Clin Microbiol. 1993;31(9):235660.

8. Al-Soud WA, Radstrom P. Purification and characterization of PCR-inhibitory components in blood cells. J Clin Microbiol. 2001;39(2):485-93.

9. Beutler E, Gelbart T, Kuhl W. Interference of heparin with the polymerase chain reaction. Biotechniques. 1990;9(2):166.

10. Hartman LJ, Coyne SR, Norwood DA. Development of a novel internal positive control for Taqman based assays. Mol Cell Probes. 2005;19(1):51-9.

11. Holodniy M, Kim S, Katzenstein D, Konrad M, Groves E, Merigan TC. Inhibition of human immunodeficiency virus gene amplification by heparin. J Clin Microbiol. 1991;29(4):676-9.

12. Ijzerman MMarian, Dahling Daniel R, Fout GShay. A method to remove environmental inhibitors prior to the detection of waterborne enteric viruses by reverse transcription-polymerase chain reaction. J Virol Methods. 1997;63(1-2):145-153.

13. Kreader CA. Relief of amplification inhibition in PCR with bovine serum albumin or T4 gene 32 protein. Appl Environ Microbiol. 1996;62(3):1102-6.

14. Tsai YL, Olson BH. Rapid method for separation of bacterial DNA from humic substances in sediments for polymerase chain reaction. Appl Environ Microbiol. 1992;58(7):2292-5.

15. Zimmermann K, Mannhalter JW. Technical aspects of quantitative competitive PCR. Biotechniques. 1996;21(2):268-72.

16. Hoorfar J, Malorny B, Abdulmawjood A, Cook N, Wagner M, Fach P. Practical considerations in design of internal amplification controls for diagnostic PCR assays.J Clin Microbiol. 2004;42(5):1863-8.

17. Tang Y, Wang Q, Saif YM. Development of a ssRNA internal control template reagent for a multiplex RT-PCR to detect turkey astroviruses. JVirol Methods. 2005;126(1-2):81-6.

18. Rosenstraus M, Wang Z, Chang SY, DeBonville D, Spadoro JP. An internal control for routine diagnostic PCR: design, properties, and effect on clinical performance. J Clin Microbiol. 1998;36(1):1917.

19. Wilson IG. Inhibition and facilitation of nucleic acid amplification. Appl Environ Microbiol. 1997;63(10):3741-51.

20. Soleimani Mohammad. Analytical specificity and sensitivity determination of 16SrRNA gene based diagnostic polymerase chain reaction (PCR) for molecular detection of Coxiella burnetii. Afr J Microbiol Res. 2012;6(36).

21. Sohni Y, Kanjilal S, Kapur V. Cloning and development of synthetic internal amplification control for Bacillus anthracis realtime polymerase chain reaction assays. Diagn Microbiol Infect Dis. 2008;61(4):471-5.

22. Hodgson J, Zuckerman M, Smith M. Development of a novel internal control for a real-time PCR for HSV DNA types 1 and 2.J Clin Virol. 2007;38(3):217-20.

23. Niesters HG. Quantitation of viral load using real-time amplification techniques. Methods. 2001;25(4):419-29.

24. Parshionikar SU, Cashdollar J, Fout GS. Development of homologous viral internal controls for use in RT-PCR assays of waterborne enteric viruses. JVirol Methods. 2004;121(1):39-48.

25. Preiser Wolfgang, Brink Nicola S, Ayliffe Ursula, Peggs Karl S, Mackinnon Stephen, Tedder Richard S, et al. Development and clinical application of a fully controlled quantitative PCR assay for cell-free cytomegalovirus in human plasma. J Clin Virol. 2003;26(1):49-59.

26. Stranska R, Schuurman R, de Vos M, van Loon AM. Routine use of a highly automated and internally controlled real-time PCR 


\section{Majidzadeh Ket al.}

assay for the diagnosis of herpes simplex and varicella-zoster virus infections. J Clin Virol. 2004;30(1):39-44.

27. Templeton KE, Scheltinga SA, Graffelman AW, Van Schie JM, Crielaard JW, Sillekens P, et al. Comparison and evaluation of real-time PCR, real-time nucleic acid sequence-based amplification, conventional PCR, and serology for diagnosis of Myco- plasma pneumoniae. J Clin Microbiol. 2003;41(9):4366-71.

28. Whiley DM, Mackay IM, Syrmis MW, Witt MJ, Sloots TP. Detection and differentiation of herpes simplex virus types 1 and 2 by a duplex LightCycler PCR that incorporates an internal control PCR reaction. J Clin Virol. 2004;30(1):32-8. 